\title{
Characteristics of EEG activity during high altitude hypoxia and lowland reoxygenation
}

Jin-ping Zhao ${ }^{a \#}$, Ran Zhang ${ }^{\text {b\# }}$, Qian $Y u^{b}$, Jia-xing Zhang ${ }^{b^{*}}$

${ }^{b}$ Health Department of Beijing Military Region Air Force Logistics Department, 100005, Beijing,

China

${ }^{b}$ Department of Physiology, Medical College of Xiamen University, Xiamen, 361102, Fujian, China

\section{Corresponding author:}

Dr. Jiaxing Zhang

Department of Physiology, Medical College of Xiamen University,

Xiamen, 361005, China

Tel: 86-0592-2188-421

Email: zhangjiaxing@xmu.edu.cn

\section{Abbreviations:}

HA; high-altitude; EEG; Electro-EncephaloGraphy 


\section{ABSTRACT}

The aim of the present study was to determine the effect of high altitude (HA) immigration on cerebral electrical activity. Electro-EncephaloGraphic (EEG) activity were recorded from 25 lowland soldiers during eyes-closed resting conditions under the following conditions: 7 days at lowland before ascending to altitude (Test 1), during the first 7 days (Test 2) and 30 days (Test 3 ) at $3800 \mathrm{~m}$ altitude, and 7 days after return to lowland (Test 4). The EEG was Fourier transformed to provide absolute and relative power estimates for the alpha, beta, delta, and theta bands. HA immigrants showed changes of EEG power confined in the posterior parietal cortex, right posterior temporal cortex, and occipital cortex. Compared with baseline Test 1 , acute acclimatization (Test 2) only decreased theta power; chronic acclimatization (Test 3) discriminately increased alpha and beta powers but decreased delta power; after descending to lowland (Test 4), alpha power decreased, beta power remained increase, but delta and theta power recovered to the baseline level. Our findings demonstrated different EEG patterns during hypoxia exposure at $\mathrm{HA}$ as time goes on and after following reoxygenation at lowland, showing hypoxia decreased lower EEG frequencies while hypoxia/reoxygenation increased higher EEG frequencies. Our findings supports for the hypothesis that certain behavioral and physiological changes induced by sojourn at altitude could be caused by alterations in central nervous system function.

\section{Keywords}

High altitude; Hypoxia; Brain; Electro-EncephaloGraphy; Reoxygenation 


\section{Introduction}

The number of people travelling to high-altitude (HA) for work, study, or training is rising. They usually stay at HA for several months to several years. For example, in China, Qinghai-Tibet Railway (average $4500 \mathrm{~m}$ ) was built by more than 100000 workers (Wu et al., 2007). Many people worked at mines in South American Andes $(4500 \mathrm{~m})$ and at Mauna Kea Observatories on the Big Island of Hawaii (4200 m) (West and Readhead, 2004). Each October, United States Antarctic Program scientists went in for work at the Amundsen-Scott South Pole Station (2835 m) (Anderson et al., 2011).

The underlying problem with HA is that there is less oxygen. With more and more people immigrating to HA, the effects of hypoxia on body have drawn more and more attention.

It is known that the electrical activity of the brain is sensitive to its oxygen supply. Abnormal Electro-EncephaloGraphy (EEG) has been generally observed in many studies of hypoxia that induced by low oxygen gas mixtures (Schellart and Reits, 2001) and by simulated HA in hypobaric chamber (Guger et al., 2008; Kraaier et al., 1988; Malle et al., 2016; Ozaki et al., 1995; Papadelis et al., 2007; Schneider et al., 2009; Shi et al., 1987), during rapid ascent to altitudes (Feddersen et al., 2015; Finnegan et al., 1985; Forster et al., 1975; Gritti et al., 2012; Guger et al., 2005; Hota et al., 2012; Kaufman et al., 1993), and in HA natives (Richardson et al., 2011).

HA immigrants have shown deficit in cognitive function (Zhang et al., 2011) and impairment in microstructure (Zhang et al., 2012; Zhang et al., 2013), which indicated an impairment of neuronal function. However, up to now little is known about characteristics of EEG in these populations. Only two studies were performed on acclimatized lowlanders, but they were not a self-control design (Hota et al., 2012; Selvamurthy et al., 1978), and among which one study was conducted on subjects with cognitive impairment (Hota et al., 2012). Moreover, after returning to lowland, some people suffered 
from “HA deadaptation reaction”' (Zhou et al., 2012), while most people did not feel any deadaptation. How reoxygenaration affects neuronal activity also remains unclear. In the present study, 25 lowland soldiers who immigrated to HA for 1 month were recruited for examining EEG activity before, during, and several days after HA exposure. We hypothesized that HA exposed brain could have different EEG patterns during hypoxia exposure at HA as time goes on and after following reoxygenation at lowland.

\section{Results}

HA immigrants showed changes of EEG power confined in the posterior parietal cortex, right temporal cortex, and occipital cortex (Fig. 1)

\subsection{Alpha power}

There were significant increases of alpha power in Test 3 vs. Test 1 at $\mathrm{Pz}$ and $\mathrm{Oz}$ and in Test 3 vs. Test 2 at Pz, P4, O1, and Oz; whereas there were significant decreases of alpha power in Test 4 vs. Test 1 at P3, in Test 4 vs. Test 2 at P3, and in Test 4 vs. Test 3 at P3, Pz, O1, and Oz (Fig. 2; Table 1).

\subsection{Beta power}

There were significant increases of beta power in Test 3 vs. Test 1 at TP8, Pz, and O2 and in Test 3 vs.

Test 2 at TP8, P4, and T6; whereas there were significant increases of beta power in Test 4 vs. Test 1 at $\mathrm{Pz}$ and $\mathrm{O} 2$ and in Test 4 vs. Test 2 at $\mathrm{P} 4$ and T6 (Fig. 3; Table 2). 
There were significant decreases of delta power in Test 3 vs. Test 1 at T4, TP8, P3, Pz, P4, Oz, and O2, in Test 3 vs. Test 2 at T4, TP8, P3, Pz, P4, T6, O1, Oz, and O2, and in Test 4 vs. Test 3 at TP8, P3, Pz, O1, Oz, and O2 (Fig. 4; Table 3).

\subsection{Theta power}

There were significant decreases in theta power in Test 2 vs. Test 1 at $\mathrm{T} 5$ and $\mathrm{O} 1$ and in Test 2 vs. Test 4 at T5 (Fig. 5; Table 4).

\section{Discussion}

To our knowledge, this is the first before-and-after study in which EEG recordings were conducted at both lowland and extreme plateau. In our study, HA immigrants showed changes of EEG power confined in the posterior parietal cortex, right temporal cortex, and occipital cortex. Compared with the baseline level tested before ascending to Lasa, acute acclimatization only decreased theta power; chronic acclimatization discriminately increased alpha and beta powers while decreased delta power; seven days after descending to lowland, beta power remained increase and alpha power decreased, with delta and theta powers recovering to the baseline level.

\section{Acute HA acclimatization decreased theta power}

In our study, in the first seven days of HA exposure, acute acclimatization only decreased theta power 
in the left temporal and occipital areas but did not change alpha, beta, and delta powers. In agree with our findings, relative theta decreased in nine males who rapid ascend to an altitude of $4300 \mathrm{~m}$ (Kaufman et al., 1993). However, in disagree with our study, increase of theta frequency has been noticed during acute normobaric hypoxia evoked by breathing a hypoxic gas (Schellart and Reits, 2001).

During acute acclimatization to HA, previous studies mainly showed the changes of beta frequency. For example, beta activity was significantly reduced $1 \mathrm{~h}$ after the cable car ride at $2700 \mathrm{~m}$ (Guger et al., 2005) and within $12 \mathrm{~h}$ in hypobaric chamber (Guger et al., 2008); in contrast, beta powers increased after a six-day marathon at $4300 \mathrm{~m}$ (Gritti et al., 2012), after 2-days' mountain (3440 m) climbing (Feddersen et al., 2015), and following a 40 min hypobaric hypoxic exposure (Schneider et al., 2009).

The different results obtained from our study and the previous studies may be related to altitude level where EEG recorded . For example, in the first stage of hypobaric hypoxia (at $3000 \mathrm{~m}$ ) alpha activity was decreased, while in a further stage starting at $5000 \mathrm{~m}$ theta activity was enhanced (Ozaki et al., 1995). Moreover, compared with simulated HA in hypobaric chamber, environmental factors such as hypothermia and hypobaria at HA can also affect physiological functions of the body (Malle et al., 2016). It has been shown that deep hypothermia reduced EEG power (Lamartine Monteiro et al., 2016; Niquet et al., 2015). In addition, the subjects in our study have acclimatized to HA since they spent 6 days gradually ascend to HA and the test was done 7 days later.

\section{Chronic HA acclimatization increased alpha and beta but decreased delta power}

In our study, after a 30-day HA exposure, chronic acclimatization discriminately increased alpha and beta powers in the middle posterior parietal and occipital areas and decreased delta power in the right 
temporal and occipital areas. In consistent with our findings, Selvamurthy et al. (1978) recorded alpha in lowlanders at HA (3500 m) from 2 up to 28 days at several time-points, respectively, and found that the mean alpha index increased and amount to $33.2 \%$ compared with lowlanders at sea level $(25.5 \%)$. In subjects with cognitive impairment staying at HA (4300 m) above 12 months, there was an increased alpha power at temporal areas (Hota et al., 2012).

Previous studies suggested that delta oscillations were generated by the interplay between the intrinsic currents from the thalamocortical cells and recorded from the nucleus accumbens, ventral tegmental area, ventral pallidum, and brain stem (Güntekin and Başar, 2014). In our previous studies, changes of neuronal activity in the pon and thalamus were found in HA residents (Yan et al., 2010; Yan et al., 2011) and an increase of gray matter volume in pon was found in the adult immigrants during adaptation to HA (Zhang et al., 2013). Therefore, we suggest the decrease of delta power in chronic HA acclimatization may be related to the functional and structural alteration in delta generated brain regions.

\section{Descending to lowland increased beta but decreased alpha power}

Up to now, no EEG recordings were conducted in HA acclimated population after their return to lowland. Beta activity is indicative of background excitation that involves a frequency potentiating mechanism at the level of synapses in a network (Whittington et al., 1997; Wrobel, 2000). Glutamatergic inputs appeared to control oscillations' strength, duration, and long range synchronization, while $\gamma$-aminobutyric acid (GABA)-ergic neurons played a pivotal role in the generation of beta oscillations and their local synchronization (Uhlhaas and Singer, 2013). Beta frequencies reflect neuronal activation with GABAA receptor action as pacemakers (Whittington et al., 
2000). In vitro study showed that hypoxia/reoxygenation increase orthodromic activity of CA1 neurons and $\mathrm{O} 2$-induced potentiation via a combination of both increased excitatory synaptic transmission and intrinsic excitability (Garcia et al., 2010). Taken together, these data suggested the changes of EEG beta in our study may be attribute to hypoxia/reoxygenation-induced neurotransmitter alteration.

\section{The significances of EEG power changes}

The different frequency bands are thought to be associated with different mental and physiological states. Alpha activity has been associated with inhibition, attention, long-range synchronization, and memory performance (Klimesch, 1999; Uhlhaas and Singer, 2013). Increases of alpha EEG activity were found in schizophrenia patient (Moore et al., 1997) and in adults with attention deficit hyperactivity disorder (Koehler et al., 2009). Beta frequency is associated with sensory gating, attention perception, and consciousness (Uhlhaas and Singer, 2013), and it is acknowledged as a marker of cognitive arousal and language processing (Weiss and Rappelsberger, 1998; Spironelli and Angrilli, 2010; Spironelli et al., 2013). Increases of beta power were found in the offspring of alcoholics (Rangaswamy et al., 2004) and Parkinson's disease (Little et al., 2014). Theta frequency is associated with intake of sensory information, memory, synaptic plasticity, top-down control long-range synchronization (Uhlhaas and Singer, 2013). Reduces of theta oscillatory activity on cognitive load were common among schizophrenia, Alzheimer's disease, attention deficit hyperactivity disorder, Parkinson's disease (Güntekin and Başar, 2014), and older adults (Lithfous et al., 2015). The limitation in the present study was that no behaviors were tested.

\section{Hypoxia-induced alteration of vertebral artery blood flow contributes to temporal and posterior EEG abnormalities}


The changes in temporal and posterior brain circulation induced by hypoxia may be related to EEG alterations shown in our present study. It is known that vertebral artery supplies blood to these parts of the brain. Willie et al. (2012) found that with profound hypoxia (35 $\mathrm{mmHg}$ ) the relative increase in vertebral artery blood flow was 50\% greater than the other vessels. Ogoh et al. (2013) found that the internal carotid artery blood flow was unchanged, while vertebral artery blood flow significantly increased during acute hypoxia. According to the finding of Sokoloff (1977) that the regional cerebral perfusion was correlated with the activity of the cortical neurons in the region, Feddersen et al. (2015) tested the relationship between cerebral perfusion and neuronal activity. They found that in mountaineers between 100 and 3440 m altitude cerebral blood flow velocity in the anterior and middle cerebral arteries increased, whereas during further ascent to $5050 \mathrm{~m}$ cerebral blood flow velocity in the posterior cerebral arteries decreased; however, hypoxia-induced increases of frontal beta activity and occipital alpha activity persisted across the entire mountain climbing. Their findings did not detect a negative or positive correlation between cerebral perfusion and neuronal activity, which seems not to support our suggestion.

\section{Conclusion}

Long-term HA exposed brain showed a different EEG pattern from that in lowlanders during rapid ascend to altitudes. Theta and delta frequencies were reduced during the period of HA exposure, suggesting hypoxia decreased lower EEG frequencies. Alpha power increased during chronic HA acclimatization but decreased after descending to lowland, suggesting hypoxia/reoxygenation may be linked to the synchronization of neuronal processes across the brain. Persist increases of beta power 
during chronic HA acclimatization and after return to lowland suggest a sustained higher level of cortical excitation during hypoxic exposure and reoxygenation. Our findings provided support for the hypothesis that certain behavioral and physiological changes induced by sojourn at altitude could be caused by alterations in central nervous system function.

\section{Experimental procedures}

\subsection{Subjects}

Twenty-five male soldiers ( $24.6 \pm 3.2$ years), who garrisoned the frontiers at Lasa $(3650 \mathrm{~m})$, Tibet, China for 1 month, were studied (Table 5). They were lowlanders born and living at lowland below 300 $\mathrm{m}$, and they were without any prior exposure to altitude. All of them were of normal body weight and body mass index. They all have no documented neurological disorder or history of head injury. The whole group had successfully completed, without the use of supplementary oxygen. Physical examinations were used to determine health status. All subjects were given written informed consent to participates in the study which had been approved by the Ethical Committee of Xiamen University.

\subsection{Physiological and neuropsychiatric measurements}

Physiological and neuropsychiatric tests were done at the same day with EEG recording. Physiological tests included the heart rate, blood pressure, and arterial oxygen saturation (SaO2). All subjects completed the Beck Depression Inventory, which assessed the severity of depression and anxiety. The 
measurements at HA also consisted of the daily observation of the Lake Louise score, with a score greater than 4 being defined as acute mountain sickness (Roach et al., 1996). All of the measurements were measured in the morning between 07:00 and 08:00 h. Moreover, deadaptation was measured at

Test 4, with 4 soldiers who had deadaptation syndrome excluded for EEG recordings. One-way ANOVA was adopted to measure group differences between the four time-point tests using SPSS (19.0). Statistical significance was set at $\mathrm{P}<0.05$.

\subsection{EEG recording procedure}

The EEG recordings were done at four stages. The first test (Test 1) was performed at Beijing (300 m), China 7 days before subject ascent to HA. Then the subjects spent 6 days leaving lowland for Lasa. The second test (Test 2) was done 7 days after subjects arriving at Lasa (acute acclimatization). The third test (Test 3) was done 30 days after subjects living at Lasa (chronic acclimatization). The last test (Test 4) was performed 7 days after subjects had returned to Beijing. The climbing schedule is shown in Fig. 6.

\section{4. $E E G$ recording}

EEG results were acquired using Neuroscan (Compumedics Ltd., Abbotsford, VIC, Australia) with a sampling rate of $500 \mathrm{~Hz}$ and 24-bit digitization. A band-pass filter with a range of $0.3-30 \mathrm{~Hz}$ was used, and the notch filter was off. Each subject underwent 15 minutes of eye-closed resting EEG testing while seated comfortably in a quiet, dimly lit, temperature-controlled, electromagnetic field shielded 
room. Vigilance was controlled by the EEG technician alerting subjects by microphone when signs of drowsiness were observed during recordings. The international 10-20 electrode system was used to position 32 electrodes with a mixed-ear reference (Fig. 1). To detect artifacts induced by eyeball movement, horizontal and vertical electrooculograms were also recorded. We selected at least 10 non-overlapping pieces of at least $15 \mathrm{sec}$ continuous artifact-free recording by a manual inspection. Data consistency was confirmed by test-retest and split-half correlations $>0.95$ per Neuroguide software (version 2.3.1. Applied Neuroscience, Inc., St. Petersburg, FL, USA). These clean epochs were subjected to a Fast Fourier Transform algorithm to calculate absolute power in delta (1-4 Hz), theta $(4-8 \mathrm{~Hz})$, alpha $(8-12 \mathrm{~Hz})$, and beta $(12-30 \mathrm{~Hz})$ bands. The relative power of each band was calculated as the fraction of total power.

\subsection{Relative power analysis}

The EEG was Fourier transformed to provide absolute and relative power estimates for the alpha, beta, delta, and theta bands. One-way ANOVA was adopted to measure between-group differences using SPSS (19.0). Statistical significance was set at $\mathrm{P}<0.05$.

\section{Funding:}

This work was supported by National Science Foundation of China (Project No. 81171324; 81471630)

and National Key project (2012CB518200). 


\section{REFERENCES}

1. Anderson, P.J., Miller, A.D., O'Malley, K.A., Ceridon, M.L., Beck, K.C., Wood, C.M., Wiste, H.J., Mueller, J.J., Johnson, J.B., Johnson, B.D., 2011. Incidence and Symptoms of High Altitude Illness in South Pole Workers: Antarctic Study of Altitude Physiology (ASAP). Clin. Med. Insights Circ. Respir. Pulm. Med. 5, 27-35.

2. Feddersen, B., Neupane, P., Thanbichler, F., Hadolt, I., Sattelmeyer, V., Pfefferkorn, T., Waanders, R., Noachtar, S., Ausserer, H., 2015. Regional differences in the cerebral blood flow velocity response to hypobaric hypoxia at high altitudes. J. Cereb. Blood Flow. Metab. 35(11), 1846-1851.

3. Finnegan, T.P., Abraham, P., Docherty, T.B., 1985. Ambulatory monitoring of the electroencephalogram in high altitude mountaineers. Electroencephalogr. Clin. Neurophysiol. 60(3), 220-224.

4. Forster, H.V., Soto, R.J., Dempsey, J.A., Hosko, M.J., 1975. Effect of sojourn at 4,300 m altitude on electroencephalogram and visual evoked response. J. Appl. Physiol. 39(1), 109-113.

5. Garcia, A.J., Putnam, R.W., Dean, J.B., 2010. Hyperbaric hyperoxia and normobaric reoxygenation increase excitability and activate oxygen-induced potentiation in CA1 hippocampal neurons. J. Appl. Physiol. (1985). 109(3), 804-819.

6. Gritti, I., Martignoni, M., Calcaterra, R., Sergio Roi, G., 2012. Electroencephalographic changes after a marathon at $4300 \mathrm{~m}$ of altitude. Journal of Behavioral and Brain Science. 2, 380-386.

7. Guger, C., Domej, W., Lindner, G., Pfurtscheller, K., Pfurtscheller, G., Edlinger, G., 2005. Effects of a fast cable car ascent to an altitude of 2700 meters on EEG and ECG. Neurosci Lett. 377(1), 53-58. 
8. Guger, C., Krausert, S., Domej, W., Edlinger, G., Tannheimer, M., 2008. EEG, ECG and oxygen concentration changes from sea level to a simulated altitude of $4000 \mathrm{~m}$ and back to sea level. Neurosci Lett. 442(2), 123-127.

9. Güntekin, B., Başar, E., 2014. A review of brain oscillations in perception of faces and emotional pictures. Neuropsychologia. 58, 33-51.

10. Hota, S.K., Sharma, V.K., Hota, K., Das, S., Dhar, P., Mahapatra, B.B., Srivastava, R.B., Singh, S.B., 2012. Multi-domain cognitive screening test for neuropsychological assessment for cognitive decline in acclimatized lowlanders staying at high altitude. Indian J. Med. Res. 136(3), 411-20.

11. Kaufman, D., Wesensten, N.J., Pearson, N.R., Kamimori, G.H., Balkin, T.J., 1993. Altitude and time of day effects on EEG spectral parameters. Physiol Behav. 54(2), 283-287.

12. Klimesch, W., 1999. EEG alpha and theta oscillations reflect cognitive and memory performance: a review and analysis. Brain Res. Brain Res. Rev. 29(2-3), 169-195.

13. Koehler, S., Lauer, P., Schreppel, T., Jacob, C., Heine, M., Boreatti-Hümmer, A., Fallgatter, A.J., Herrmann, M.J., 2009. Increased EEG power density in alpha and theta bands in adult ADHD patients. J. Neural. Transm (Vienna). 116(1), 97-104.

14. Kraaier V, Van Huffelen AC, Wieneke GH., 1988. Quantitative EEG changes due to hypobaric hypoxia in normal subjects. Electroencephalogr. Clin. Neurophysiol. 69(4), 303-312.

15. Lamartine Monteiro, M., Taccone, F.S., Depondt, C., Lamanna, I., Gaspard, N., Ligot, N., Mavroudakis, N., Naeije, G., Vincent, J.L., Legros, B., 2016. The Prognostic Value of 48-h Continuous EEG During Therapeutic Hypothermia After Cardiac Arrest. Neurocrit. Care. 24(2), 153-162. 
16. Lithfous, S., Tromp, D., Dufour, A., Pebayle, T., Goutagny, R., Després, O., 2015. Decreased theta power at encoding and cognitive mapping deficits in elderly individuals during a spatial memory task. Neurobiol. Aging 36(10), 2821-2829.

17. Little, S., Brown, P., 2014. The functional role of beta oscillations in Parkinson's disease. Parkinsonism Relat. Disord. 20(Suppl), S44-48.

18. Malle, C., Bourrilhon, C., Quinette, P., Laisney, M., Eustache, F., Piérard, C., 2016. Physiological and Cognitive Effects of Acute Normobaric Hypoxia and Modulations from Oxygen Breathing. Aerosp. Med. Hum. Perform. 87(1), 3-12.

19. Moore, N.C., Tucker, K.A., Brin, F.B., Merai, P., Shillcutt, S.D., 1997. Positive Symptoms of Schizophrenia: Response to Haloperidol and Remoxipride is Associated with Increased Alpha EEG Activity. Human Psychopharmacology Clinical \& Experimental. 12(1), 75-80.

20. Niquet, J., Gezalian, M., Baldwin, R., Wasterlain, C.G., 2015. Neuroprotective effects of deep hypothermia in refractory status epilepticus. Ann. Clin. Transl. Neurol. 2(12), 1105-1115.

21. Ogoh, S., Sato, K., Nakahara, H., Okazaki, K., Subudhi, A.W., Miyamoto, T., 2013. Effect of acute hypoxia on blood flow in vertebral and internal carotid arteries. Exp. Physiol. 98(3), 692-698.

22. Ozaki, H., Watanabe, S., Suzuki, H., 1995. Topographic EEG changes due to hypobaric hypoxia at simulated high altitude. Electroencephalogr. Clin. Neurophysiol. 94(5), 349-356.

23. Papadelis, C., Kourtidou-Papadeli, C., Bamidis, P.D., Maglaveras, N., Pappas, K., 2007. The effect of hypobaric hypoxia on multichannel EEG signal complexity. Clin. Neurophysiol. 118(1), $31-52$.

24. Rangaswamy, M., Porjesz, B., Chorlian, D.B., Wang, K., Jones, K.A., Kuperman, S., Rohrbaugh, 
J., O'Connor, S.J., Bauer, L.O., Reich, T., Begleiter, H., 2004. Resting EEG in offspring of male alcoholics: beta frequencies. Int. J. Psychophysiol. 51(3), 239-251.

25. Richardson, C., Hogan, A.M., Bucks, R.S., Baya, A., Virues-Ortega, J., Holloway, J.W., Rose-Zerilli, M., Palmer, L.J., Webster, R.J., Kirkham, F.J., Baldeweg, T., 2011. Neurophysiological evidence for cognitive and brain functional adaptation in adolescents living at high altitude. Clin. Neurophysiol. 122(9), 1726-1734.

26. Roach, R.C., Loeppky, J.A., Icenogle, M.V., 1996. Acute mountain sickness: Increased severity during simulated altitude compared with normobaric hypoxia. J. Appl. Physiol. 81(5), 1908-1910.

27. Schellart, N.A., Reits, D., 2001. Transient and maintained changes of the spontaneous occipital EEG during acute systemic hypoxia. Aviat. Space Environ. Med. 72(5), 462-470.

28. Schneider, S., Strüder, H.K., 2009. Monitoring effects of acute hypoxia on brain cortical activity by using electromagnetic tomography. Behav. Brain Res. 197(2), 476-480.

29. Selvamurthy, W., Saxena, R.K., Krishnamurthy, N., Suri, M.L., Malhotra, M.S., 1978. Changes in EEG pattern during acclimatization to high altitude $(3500 \mathrm{~m})$ in man. Aviat Space Environ Med. 49(8), 968-971.

30. Shi, Z., Zhao, D., Gu, Z., 1987. The influence of acute and chronic hypoxia on the electroencephalogram of human body. Ann. Physiol. Anthropol. 6(3), 111-121.

31. Sokoloff, L., 1977. Relation between physiological function and energy metabolism in the central nervous system. J. Neurochem. 29(1):13-26.

32. Spironelli, C., Angrilli, A., 2010. Developmental aspects of language lateralization in delta, theta, alpha and beta EEG bands. Biol. Psychol. 85(2), 258-267.

33. Spironelli, C., Manfredi, M., Angrilli, A., 2013. Beta EEG band: A measure of functional brain 
damage and language reorganization in aphasic patients after recovery. Cortex. 49(10), $2650-2660$.

34. Uhlhaas, P.J., Singer, W., 2013. High-frequency oscillations and the neurobiology of schizophrenia. Dialogues Clin. Neurosci. 15(3), 301-313.

35. Weiss, S., Rappelsberger, P., 1998. Left frontal EEG coherence reflects modality independent language processes. Brain Topogr. 11(1), 33-42.

36. West, J.B., Readhead, A., 2004. Working at high altitude: medical problems, misconceptions, and solutions. Observatory 124(1178), 1-13.

37. Whittington, M.A., Faulkner, H.J., Doheny, H.C., Traub, R.D., 2000. Neuronal fast oscillations as target site for psychoactive drugs. Pharmacol. Ther. 86(2), 171-190.

38. Whittington, M.A., Traub, R.D., Faulkner, H.J., Stanford, I.M., Jefferys, J.G., 1997. Recurrent excitatory postsynaptic potentials induced by synchronized fast corticaloscillations. Proc. Natl. Acad. Sci. U S A 94(22), 12198-12203.

39. Willie, C.K., Macleod, D.B., Shaw, A.D., Smith, K.J., Tzeng, Y.C., Eves, N.D., Ikeda, K., Graham, J., Lewis, N.C., Day, T.A., Ainslie, P.N., 2012. Regional brain blood flow in man during acute changes in arterial blood gases. J. Physiol. 590(14), 3261-3275.

40. Wróbel, A., 2000. Beta activity: a carrier for visual attention. Acta Neurobiol. Exp (Wars). 60(2), 247-260.

41. Wu, T.Y., Ding, S.Q., Liu, J.L., Yu, M.T., Jia, J.H., Chai, Z.C., Dai, R.C., Zhang, S.L., Li, B.Y., Pan, L., Liang, B.Z., Zhao, J.Z., Qi de, T., Sun, Y.F., Kayser, B., 2007. Who should not go high: chronic disease and work at altitude during construction of the Qinghai-Tibet railroad. High Alt. Med. Biol. 8(2), 88-107. 
42. Yan, X., Zhang, J., Gong, Q., Weng, X., 2011. Cerebrovascular reactivity among native-raised high altitude residents: an fMRI study. BMC Neurosci. 12, 94.

43. Yan, X., Zhang, J., Shi, J., Gong, Q., Weng, X., 2010. Cerebral and functional adaptation with chronic hypoxia exposure: a multi-modal MRI study. Brain Res. 1348, 21-29.

44. Zhang, H., Lin, J., Sun, Y., Huang, Y., Ye, H., Wang, X., Yang, T., Jiang, X., Zhang, J., 2012. Compromised white matter microstructural integrity after mountain climbing: evidence from diffusion tensor imaging. High Alt. Med. Biol. 13(2), 118-125.

45. Zhang, J., Liu, H., Yan, X., Weng, X., 2011. Minimal effects on human memory following long-term living at moderate altitude. High Alt. Med. Biol. 12(1), 37-43.

46. Zhang, J., Zhang, H., Li, J., Chen, J., Han, Q., Lin, J., Yang, T., Fan, M., 2013. Adaptive modulation of adult brain gray and white matter to high altitude: structural MRI studies. PLoS One 8, e68621.

47. Zhou, Q., Yang, S., Luo, Y., Qi, Y., Yan, Z., Shi, Z., Fan, Y., 2012. A randomly-controlled study on the cardiac function at the early stage of return to the plains after short-term exposure to high altitude. PLoS One 7, e31097. 


\section{FIGURE LEGENDS}

Fig. 1 -Graphical representation of the changes of EEG power located at the brain.

Fig. 2 - Changes of alpha power during high altitude exposure and after return to lowland. *, $\mathrm{P}<0.05$;

$* *, \mathrm{P}<0.01$

Fig. 3 - Changes of beta power during high altitude exposure and after return to lowland. *, $\mathrm{P}<0.05$;

$* *, \mathrm{P}<0.01$.

Fig. 4 - Changes of delta power during high altitude exposure and after return to lowland. *, $\mathrm{P}<0.05$;

$* *, \mathrm{P}<0.01 ; * * *, \mathrm{P}<0.001$.

Fig. 5 - Changes of theta power during high altitude exposure and after return to lowland. *, $\mathrm{P}<0.05$;

$* *, \mathrm{P}<0.01$.

Fig. 6 - Schedule of the soldiers garrisoned the frontiers at high altitude. 

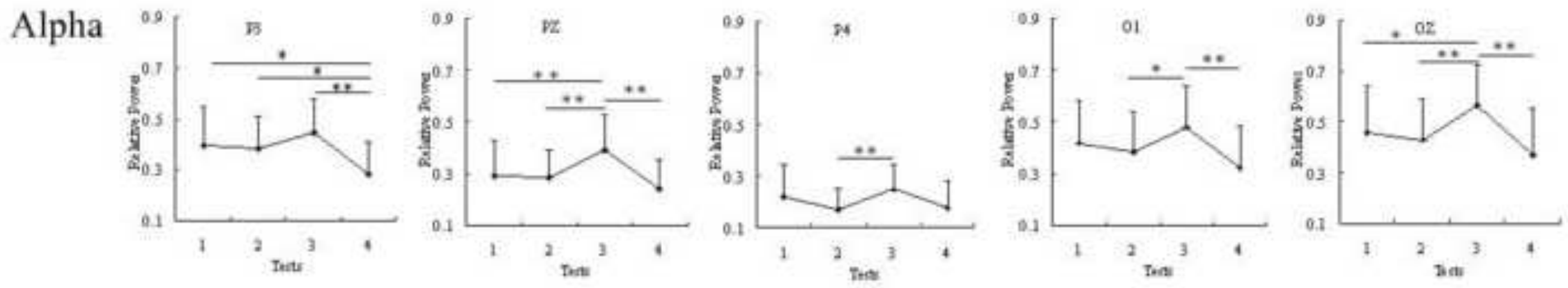

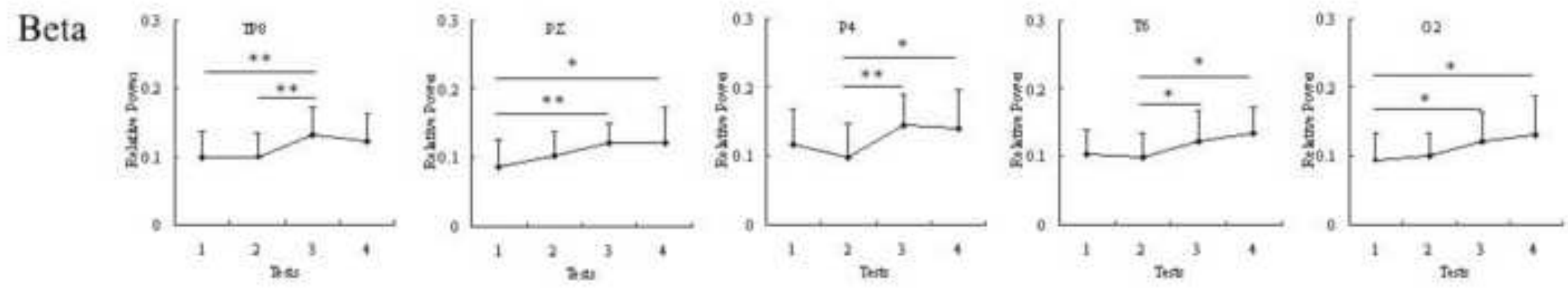
Delta
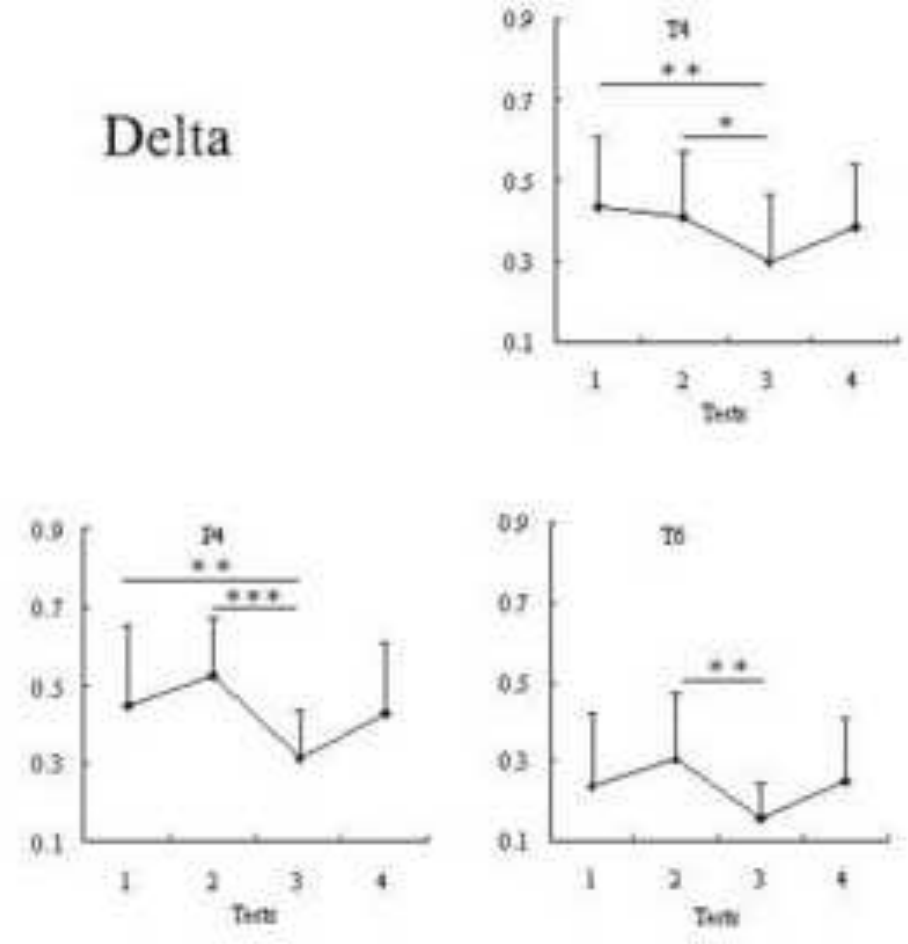
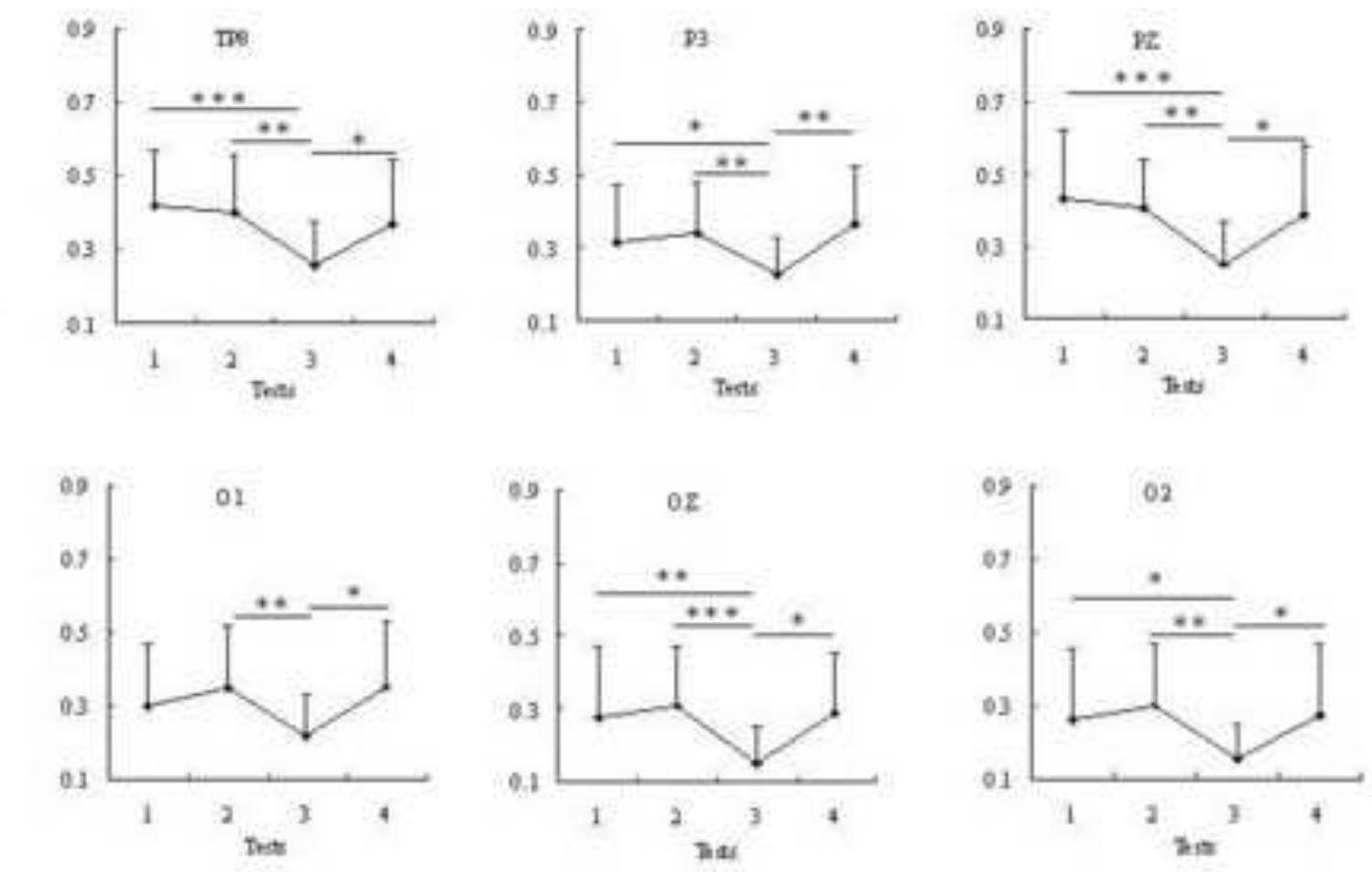

\section{Figure}



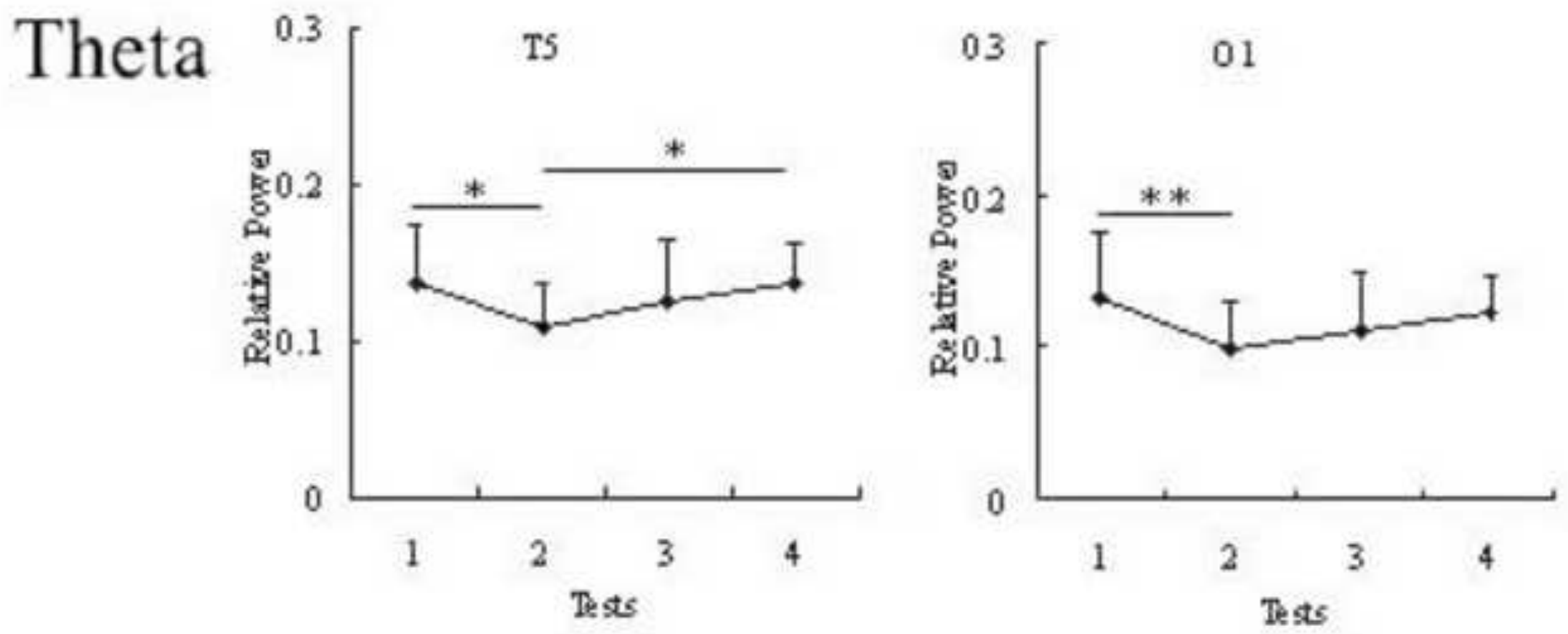

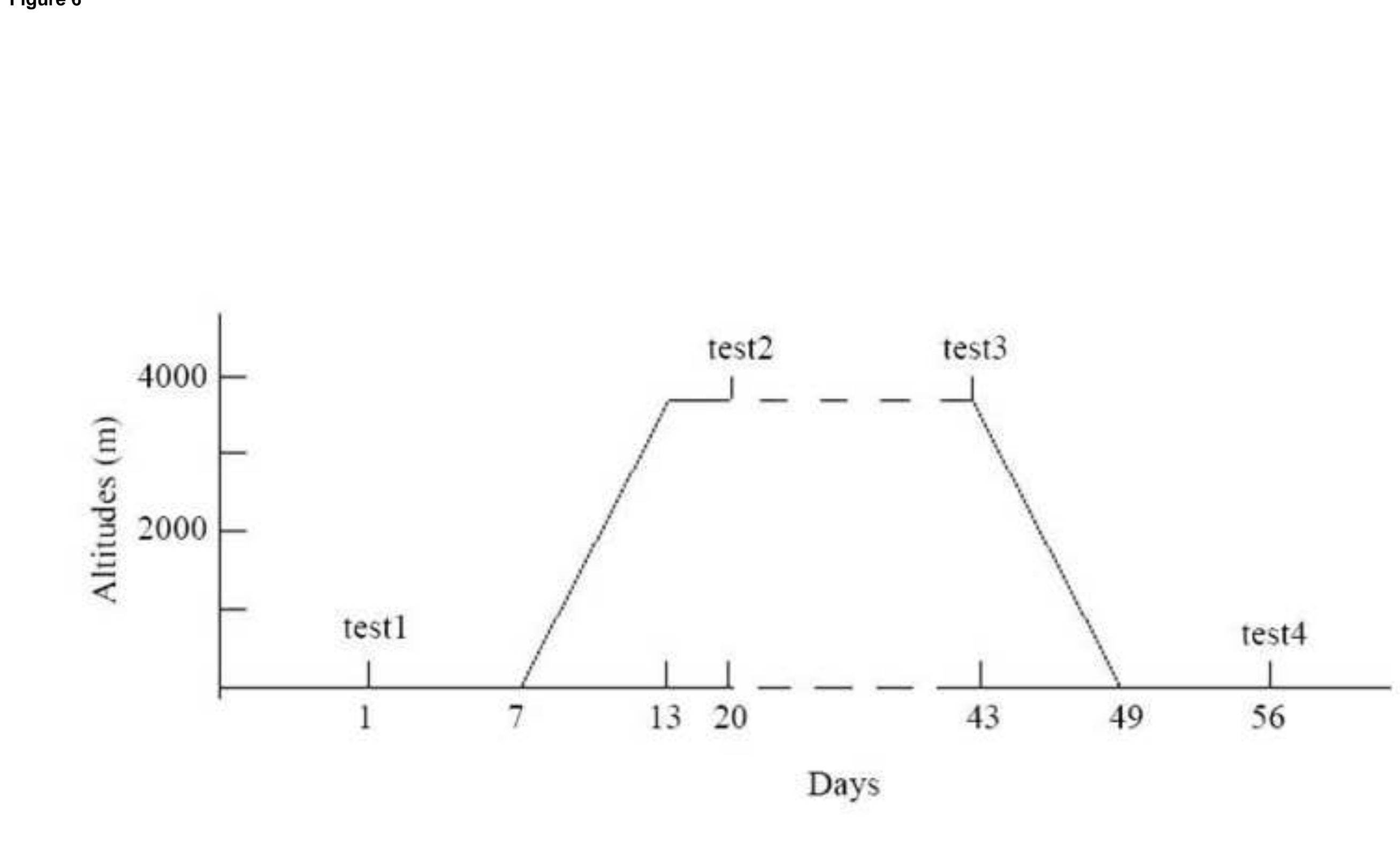

.

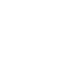

$$
\text { . }
$$

\section{Days}


Table 1 - Alpha power of the subjects.

\begin{tabular}{|c|c|c|c|c|c|c|c|c|c|c|}
\hline & Test 1 & Test 2 & Test 3 & Test 4 & $\mathrm{P} 1$ & $\mathrm{P} 2$ & P3 & P4 & P5 & P6 \\
\hline P3 & $0.392(0.15)$ & $0.386(0.12)$ & $0.446(0.14)$ & $0.282(0.12)$ & & & 0.038 & & 0.047 & 0.002 \\
\hline $\mathrm{PZ}$ & $0.289(0.14)$ & $0.286(0.10)$ & $0.392(0.14)$ & $0.238(0.12)$ & & 0.009 & & 0.005 & & 0.002 \\
\hline P4 & $0.219(0.12)$ & $0.171(0.07)$ & $0.249(0.09)$ & $0.176(0.10)$ & & & & 0.009 & & \\
\hline $\mathrm{O} 1$ & $0.418(0.17)$ & $0.385(0.15)$ & $0.482(0.15)$ & $0.319(0.16)$ & & & & 0.039 & & 0.008 \\
\hline $\mathrm{OZ}$ & $0.457(0.18)$ & $0.430(0.16)$ & $0.564(0.16)$ & $0.368(0.18)$ & & 0.042 & & 0.008 & & 0.003 \\
\hline
\end{tabular}

P1 ,Test 2 vs. Test 1; P2 ,Test 3 vs. Test 1; P3 ,Test 4 vs. Test 1; P4 ,Test 3 vs. Test 2; P5 ,Test 4 vs. Test 2; P6 ,Test 4 vs. Test 3.

Data are shown as mean(SD). 
Table 2 -Beta power of the subjects.

\begin{tabular}{|c|c|c|c|c|c|c|c|c|c|c|}
\hline & Test 1 & Test 2 & Test 3 & Test 4 & $\mathrm{P} 1$ & $\mathrm{P} 2$ & $\mathrm{P} 3$ & $\mathrm{P} 4$ & P5 & P6 \\
\hline TP8 & $0.098(0.04)$ & $0.099(0.03)$ & $0.133(0.04)$ & $0.122(0.04)$ & & 0.005 & 0.004 & & & \\
\hline PZ & $0.086(0.04)$ & $0.103(0.04)$ & $0.120(0.03)$ & $0.120(0.05)$ & & 0.003 & 0.018 & & & \\
\hline P4 & $0.116(0.06)$ & $0.098(0.05)$ & $0.145(0.04)$ & $0.139(0.05)$ & & & & 0.002 & 0.032 & \\
\hline T6 & $0.103(0.04)$ & $0.097(0.04)$ & $0.123(0.04)$ & $0.135(0.05)$ & & & & 0.033 & 0.016 & \\
\hline $\mathrm{O} 2$ & $0.094(0.04)$ & $0.100(0.03)$ & $0.123(0.04)$ & $0.131(0.05)$ & & & 0.018 & & 0.043 & \\
\hline
\end{tabular}

P1 ,Test 2 vs. Test 1; P2 ,Test 3 vs. Test 1; P3, Test 4 vs. Test 1; P4, Test 3 vs. Test 2; P5 ,Test 4 vs. Test 2 ; P6,Test 4 vs. Test 3.

Data are shown as mean(SD). 
Table 3 -Delta power of the subjects.

\begin{tabular}{|c|c|c|c|c|c|c|c|c|c|c|}
\hline & Test 1 & Test 2 & Test 3 & Test 4 & $\mathrm{P} 1$ & $\mathrm{P} 2$ & P3 & $\mathrm{P} 4$ & P5 & P6 \\
\hline $\mathrm{T} 4$ & $0.433(0.17)$ & $0.407(0.16)$ & $0.299(0.14)$ & $0.384(0.20)$ & & 0.009 & & 0.026 & & \\
\hline TP8 & $0.418(0.14)$ & $0.400(0.16)$ & $0.258(0.10)$ & $0.372(0.17)$ & & $<0.001$ & & 0.001 & & 0.040 \\
\hline P3 & $0.315(0.15)$ & $0.339(0.14)$ & $0.227(0.11)$ & $0.363(0.14)$ & & 0.050 & & 0.005 & & 0.009 \\
\hline PZ & $0.433(0.18)$ & $0.404(0.13)$ & $0.252(0.10)$ & $0.387(0.17)$ & & $<0.001$ & & 0.001 & & 0.017 \\
\hline P4 & $0.446(0.21)$ & $0.524(0.14)$ & $0.311(0.11)$ & $0.428(0.17)$ & & 0.007 & & $<0.001$ & & \\
\hline T6 & $0.240(0.17)$ & $0.306(0.17)$ & $0.154(0.08)$ & $0.250(0.16)$ & & & & 0.001 & & \\
\hline $\mathrm{O} 1$ & $0.301(0.16)$ & $0.348(0.16)$ & $0.218(0.12)$ & $0.350(0.16)$ & & & & 0.004 & & 0.022 \\
\hline $\mathrm{OZ}$ & $0.278(0.19)$ & $0.311(0.16)$ & $0.148(0.10)$ & $0.290(0.15)$ & & 0.006 & & $<0.001$ & & 0.016 \\
\hline $\mathrm{O} 2$ & $0.262(0.19)$ & $0.299(0.17)$ & $0.150(0.09)$ & $0.271(0.18)$ & & & & 0.002 & & 0.046 \\
\hline
\end{tabular}

P1 ,Test 2 vs. Test 1 ; P2 ,Test 3 vs. Test 1; P3, Test 4 vs. Test 1; P4 ,Test 3 vs. Test 2; P5 ,Test 4 vs. Test 2; P6,Test 4 vs. Test 3.

Data are shown as mean(SD). 
Table 4-Theta power of the subjects.

\begin{tabular}{|c|c|c|c|c|c|c|c|c|c|c|}
\hline & Test 1 & Test 2 & Test 3 & Test 4 & P1 & $\mathrm{P} 2$ & P3 & $\mathrm{P} 4$ & P5 & P6 \\
\hline $\mathrm{T} 5$ & $0.136(0.04)$ & $0.108(0.03)$ & $0.125(0.04)$ & $0.137(0.03)$ & 0.011 & & & & 0.034 & \\
\hline $\mathrm{O} 1$ & $0.133(0.04)$ & $0.100(0.03)$ & $0.111(0.04)$ & $0.123(0.02)$ & 0.003 & & & & & \\
\hline
\end{tabular}

$\mathrm{P} 1$,Test 2 vs. Test 1; P2 ,Test 3 vs. Test 1; P3 ,Test 4 vs. Test 1; P4 ,Test 3 vs. Test 2; P5 ,Test 4 vs. Test 2; P6 ,Test 4 vs. Test 3.

Data are shown as mean(SD). 
Table 5 - Demographic and physiological characteristics of the subjects.

\begin{tabular}{|c|c|c|c|c|}
\hline & Test 1 & Test 2 & Test 3 & Test 4 \\
\hline \multirow[t]{4}{*}{ Drug therapy } & & rhodiola rosea ( 2 persons), 21 & stomach-recovering & \\
\hline & & super-vita (5 persons), armillarisin A & capsule (1 person), 21 & \\
\hline & & (1 person), paracetamol, amoxicillin & super-vita (1 person) & \\
\hline & & cow-bezoar (1 person) & & \\
\hline \multicolumn{5}{|l|}{ Blood pressure } \\
\hline Systolic pressure & $118.1 \pm 10.9$ & $130.0 \pm 12.5^{* * * \# \# \#}$ & $125.3 \pm 7.9^{* * \# \# \#}$ & $106.0 \pm 8.2^{* * *}$ \\
\hline Diastolic pressure & $75.0 \pm 7.7$ & $77.6 \pm 9.3$ & $76.7 \pm 8.5$ & $73.6 \pm 6.6$ \\
\hline Heart-rate & $71.0 \pm 10.1$ & 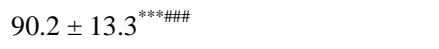 & $90.0 \pm 8.9^{* * * \# \# \#}$ & $70.9 \pm 11.9$ \\
\hline $\mathrm{SaO} 2$ & $97.7 \pm 0.9$ & $90.3 \pm 3.2^{* * * \# \# \#}$ & $92.5 \pm 3.2^{* * * \# \# \#}$ & $97.4 \pm 1.8$ \\
\hline Lake Louise Score & & $0.8 \pm 1.1$ & $0.6 \pm 1.1$ & $0.5 \pm 1.5$ \\
\hline Beck's score & $7.3 \pm 1.0$ & & $7.2 \pm 1.0$ & $7.1 \pm 1.1$ \\
\hline
\end{tabular}

*, Test $2,3,4$ vs. Test $1 . * *, \mathrm{P}<0.01 ; * * *, \mathrm{P}<0.001$

\#, Test 1, 2, 3 vs. Test 4. ${ }^{\# \#}, \mathrm{P}<0.001$

Data are shown as mean $\pm \mathrm{SD}$. 